\title{
Adoção, seleção e implantação de um ERP livre
}

\author{
Juliano Correa ${ }^{a *}$, Mauro de Mesquita Spinola ${ }^{\mathrm{b}}$ \\ aUniversidade Federal de Minas Gerais, Belo Horizonte, MG, Brasil \\ bUniversidade de São Paulo, São Paulo, SP, Brasil \\ *julianocorrea@ufmg.br
}

\section{Resumo}

Na década de 1990, os sistemas ERP alcançaram larga utilização. Em contrapartida, o interesse por software livre data dos primeiros desenvolvimentos nas décadas de 1960 e 1970 até os dias atuais. 0 problema desta pesquisa está em como adotar, selecionar e implantar um ERP livre. As contribuições do trabalho iniciam-se com a proposição de um modelo preliminar de ciclo de vida de ERP, considerando não haver distinções entre o modelo para um ERP proprietário ou livre. Refina-se este modelo inicial através da aplicação do método de pesquisa-ação em um trabalho de campo com a implantação de um ERP livre em uma organização brasileira. 0 principal resultado deste trabalho é um modelo final para adoção, seleção e implantação de ERP livres e proprietários. Nos processos de adoção e seleção, são destacadas as diferenças fundamentais para atender a ERP livres e proprietários. Em relação ao processo de implantação, não foram encontradas distinções significativas.

Palavras-chave

ERP. Software livre. Código aberto. Pesquisa-ação.

\section{Introdução}

Na década de 1990, os sistemas ERP (Enterprise Resource Planning) alcançaram larga utilização. Atualmente, com a saturação deste mercado, os principais fornecedores destes sistemas focaram sua estratégia para atuação também em empresas de pequeno e médio porte, que passaram a ficar sob intensa campanha publicitária das empresas fornecedoras destes sistemas e, muitas vezes, sem referencial para avaliar a aquisição.

Verifica-se que não são baixas as expectativas advindas de investimentos em um ERP (Corrêa et al., 1997, Corrêa, 1998, Mendes \& Escrivão Filho, 2002). Segundo Corrêa (1998), os executivos não esperam pouco destes sistemas.

Em contrapartida, o interesse por sistemas de código aberto data dos primeiros sistemas de software desenvolvidos nas décadas de 1960 e 1970, que já nasceram abertos. Nos anos 1990, com a disseminação de sistemas operacionais proprietários, a discussão de código aberto restringiu-se a esse tipo de software.
Na década atual, com significativa base instalada dos sistemas operacionais de código aberto utilizados em servidores de uso corporativo, com boa qualidade de software, o caminho natural tornou-se a criação de aplicativos nesse modelo como: gerenciamento do relacionamento com clientes ou CRM (Customer Relationship Management), soluções de gestão do conhecimento ou KM (Knowledge Management) e sistemas ERP (Enterprise Resource Planning), entre outros (Ryman, 2004; Raymond, 1999).

0 desenvolvimento da pesquisa com foco em adoção, seleção e implantação de um ERP livre visa contribuir para empresas que buscam adotar o uso da tecnologia apresentando alternativas que podem eliminar possíveis gargalos de investimentos cogitando a utilização de um ERP desenvolvido na forma de software livre.

Visa também apresentar, como trabalho de campo, um caso real de adoção, seleção e implantação de um ERP livre realizado pelo autor em uma ONG (Organização não Governamental), o Portal da Ajuda. 
Este trabalho de campo deu apoio à análise e validação de um modelo de ciclo de vida de um ERP.

0 artigo está estruturado de forma que os problemas e objetivos da pesquisa são mostrados no capítulo 2, a fundamentação teórica no capítulo 3, a metodologia da pesquisa no capítulo 4 , o modelo inicial no capítulo 5, o trabalho de campo no capítulo 6 , o modelo ajustado no capítulo 7 e, finalmente, a conclusão no capítulo 8.

\section{Problema e objetivos}

O software livre, por ter seu código disponível para livre acesso de qualquer pessoa, apresenta algumas vantagens em relação ao custo de aquisição, possibilidade de personalização e independência de tecnologia ou fornecedor. Essas vantagens, especialmente o custo, atraem as pequenas empresas, que possuem reduzidos capitais para investimento na diferenciação através da tecnologia da informação (Zimmerer \& Scarborough, 1994).

Os sistemas ERP, em contraponto, podem vir a constituir fator de competitividade para as empresas, especialmente as pequenas e médias, uma vez que grande parte das grandes empresas já possui tais sistemas (Corrêa, 1998).

Esta pesquisa tem como objeto de estudo os sistemas ERP desenvolvidos sob o modelo de software livre com foco na adoção, seleção e na implantação desses sistemas.

Assim, o problema desta pesquisa pode ser assim expresso: Como adotar e selecionar um ERP livre? Como implantar um ERP livre?

Com o problema da pesquisa definido, os objetivos da pesquisa podem ser descritos como:

1. Propor, aprimorar e aperfeiçoar um modelo de ciclo de vida para ERP (livre e proprietário);
2. Identificar e discutir características especiais dos processos de adoção, seleção e implantação de ERP Livre.

\section{Fundamentação teórica}

Alguns conceitos fundamentais para o desenvolvimento da pesquisa "adoção, seleção e implantação de um ERP livre" são o entendimento do que é Software Livre e a definição das características dos sistemas ERP.

\subsection{Definição de sistema ERP}

0 sistema ERP é uma evolução dos primeiros sistemas de software aplicados às organizações. Até a década de 1960, as áreas da organização continuavam utilizando sistemas isolados para tarefas como processar folhas de pagamento, financeiro, contabilidade e outros, com complexas integrações e redundância de dados. Já os métodos para o gerenciamento de estoques e compras de manufatura, segundo Orlicky (1973), eram quase que exclusivamente estatístico sobre o histórico de consumo ou reativo com ponto de reposição dos insumos.

Assim, no final da década de 1980, um novo conceito de software foi apresentado com a finalidade de abranger todas as áreas da organização, agrupando as funcionalidades dos diversos sistemas de software "isolados" em um único sistema que abrangesse desde folha de pagamento, contabilidade, financeiro, compras, vendas, até os processos industriais. Assim surgiram os primeiros sistemas ERP, com o grande diferencial de substituir os diversos sistemas isolados, eliminando redundância de dados e com funcionalidades abrangentes que cobrem diversas áreas da organização de forma orientada a processos.

Na Figura 1, podemos verificar uma representação gráfica adaptada da figura de Colangelo Filho (2001) sobre a evolução dos sistemas ERP e a abrangência da solução nas áreas funcionais de uma empresa.

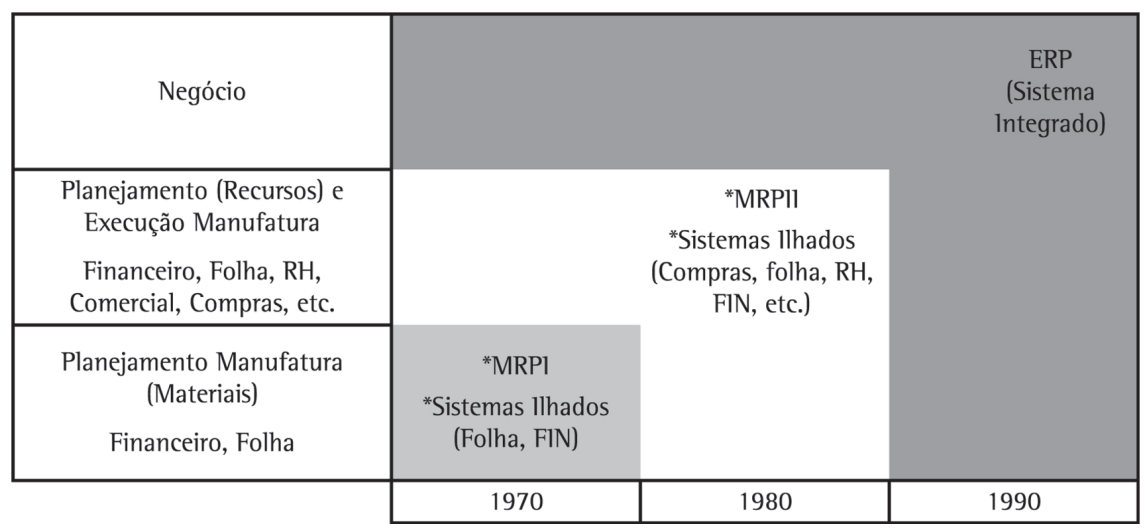

Figura 1. Evolução dos sistemas ERP. Fonte: Adaptado de Colangelo Filho (2001). 
Sistemas ERP têm diversas definições na literatura. Mendes \& Escrivão Filho (2002) listam as principais características atribuídas a um sistema ERP pelos principais autores, e uma matriz foi montada, resultando nas características mais citadas que caracterizam um sistema ERP. A Tabela 1 apresenta o resultado deste trabalho.

Verifica-se que as características citadas por ao menos metade dos autores para definir um ERP são as marcadas na Tabela 1. Essa é, portanto, a definição de ERP que norteará este trabalho e será utilizada para caracterizar um sistema ERP.

Laurindo \& Mesquita (2000) defendem que os custos da implantação vão além da compra pura e simples do software, sendo que os demais custos (como os de consultorias e de treinamento) costumam ser de três a cinco vezes maiores. Bingi et al. (1999) defendem que quanto maior o grau de "customização", maiores os custos de implantação. Já Esteves et al. (2000) defendem que existem custos tangíveis e intangiveis vinculados ao ciclo de vida de um ERP. Nas pesquisas de campo destes autores, a fase de implantação, baseada quase que totalmente em serviços, teve custo, no mínimo, 3 vezes maior que o da fase de adoção em que licenças de software e hardware foram adquiridas.

Importante conceito também é o ciclo de vida de sistemas ERP, no qual se delimitam as fases da vida. As fases mais comuns adotadas na maioria dos modelos tratam desde a adoção, seleção, implantação, manutenção, evolução até o abandono do ERP.

\subsection{Software livre}

0 software nasceu livre desde o desenvolvimento da informática nos anos 1960 e na primeira metade da década de 1970, visto que normalmente o sistema operacional e os aplicativos eram fornecidos para cada arquitetura de computador, sendo o foco principal dos fabricantes o desenvolvimento do hardware. Esse cenário começou a mudar a partir da segunda metade da década de 1970, quando seu licenciamento começa a tomar corpo e fomenta a criação da primeira iniciativa de software livre (Saleh, 2004).

É pertinente ressaltar que, apesar de software livre poder ser vendido, pois a palavra free do inglês refere-se a garantias de liberdade, não gratuidade, o custo da

Tabela 1. Características dos sistemas ERP.

\begin{tabular}{|c|c|c|c|c|c|c|c|c|c|c|c|c|c|c|c|}
\hline $\begin{array}{l}\text { Autores } \\
\text { Características }\end{array}$ & 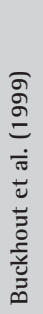 & 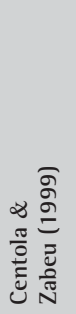 & 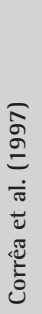 & 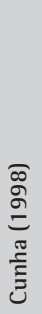 & 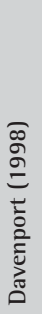 & 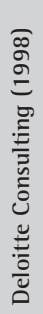 & 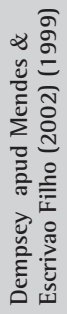 & 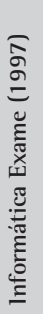 & 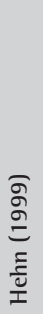 & 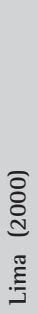 & 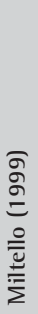 & 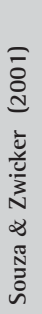 & 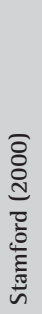 & 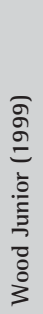 & \\
\hline Auxilia a tomada de decisão & & & $X$ & $x$ & & & & & & & & & & $x$ & 3 \\
\hline $\begin{array}{l}\text { Atende a todas as áreas da } \\
\text { empresa }\end{array}$ & $x$ & & $x$ & $x$ & $x$ & & $x$ & $x$ & $x$ & $x$ & & $x$ & $x$ & & 10 \\
\hline $\begin{array}{l}\text { Possui base de dados única e } \\
\text { centralizada }\end{array}$ & & & $x$ & & & $x$ & & & $x$ & & $x$ & $x$ & $x$ & $x$ & 7 \\
\hline $\begin{array}{l}\text { Possibilita maior controle sobre } \\
\text { a empresa }\end{array}$ & & & $x$ & & & & & $X$ & & $x$ & $X$ & & & $x$ & 5 \\
\hline Evolução do MRPIl & & & $x$ & $x$ & & & & & $x$ & & & & & & 3 \\
\hline $\begin{array}{l}\text { Obtém a informação em tempo } \\
\text { real }\end{array}$ & & & & & & $x$ & & & & $x$ & & & $x$ & $x$ & 4 \\
\hline $\begin{array}{l}\text { Permite a integração das áreas } \\
\text { da empresa }\end{array}$ & $x$ & & $X$ & $x$ & $x$ & $x$ & $x$ & & $x$ & & & $x$ & & $x$ & 9 \\
\hline Possui modelos de referência & & & & $x$ & & & & & $x$ & & & $x$ & & & 3 \\
\hline É um sistema genérico & & & & $x$ & & & & & & & & & $X$ & $\mathrm{X}$ & 3 \\
\hline $\begin{array}{l}\text { Oferece suporte ao planejamento } \\
\text { estratégico }\end{array}$ & & $x$ & & $x$ & $x$ & & & & $x$ & & & & & & 4 \\
\hline $\begin{array}{l}\text { Apoia a necessidade de } \\
\text { informação das áreas }\end{array}$ & $x$ & $x$ & $x$ & $x$ & $x$ & $x$ & $x$ & & & & $x$ & $x$ & & & 9 \\
\hline Apoia as operações da empresa & $x$ & & & & & & & & & & & $x$ & & & 2 \\
\hline $\begin{array}{l}\text { É uma ferramenta de mudança } \\
\text { organizacional }\end{array}$ & & & & & & & & $x$ & & $x$ & & & & & 2 \\
\hline Orientação a processos & & $X$ & & $x$ & & $x$ & & $x$ & $x$ & $x$ & $x$ & $X$ & $X$ & $x$ & 10 \\
\hline
\end{tabular}

Fonte: Adaptado de Mendes \& Escrivão Filho (2002). 
licença de sistemas de software livres normalmente é muito baixo ou próximo de zero (Hexsel, 2002). lsto se explica pelo modelo de produção do software livre, pois, segundo Saleh (2004), o custo principal para produção do software é o seu desenvolvimento, já que, uma vez produzido, não existe grande custo em sua distribuição. E o mesmo produto de software livre pode ser distribuído para quantos usuários o quiserem, conforme uma das garantias deste modelo de desenvolvimento.

Um questionamento recorrente quando se pesquisa software livre é "Se o custo de aquisição do SL é muito baixo, como sobrevivem as empresas e comunidades que desenvolvem sob este modelo?". Na verdade, o negócio de software livre tem como foco a venda de serviços, acreditando ser esta a maneira para criação de valor e sustentabilidade do modelo de negócio (Saleh, 2004).

Outro questionamento é a diferença entre software livre e software de código aberto, capitaneado respectivamente pelas fundações FSF - Free Software Foundation (2005) e OSI - Open Source Initiative (2006). Segundo Campos (2006), a diferença entre os movimentos de software livre e de código aberto tem sido contestada dentro da própria comunidade. Segundo este autor, o código aberto é uma metodologia de desenvolvimento enquanto o software livre é um movimento social. São como dois partidos políticos dentro de uma mesma comunidade, que concordam em diversas ações práticas e não se consideram inimigos, mas discordam em alguns princípios. Na prática, a diferença entre software livre e código aberto está nas formas de licenciamento dos sistemas.

Para efeito deste estudo, adotaremos a definição mais restritiva da FSF, e somente serão considerados como ERP livres os sistemas de software certificados com licença compatível com o tipo de licenciamento GPL - General Public licence (Open Source Iniciative, 2006) patrocinada pela fundação FSF (Free Software Foundation, 2005).

Campos (2006), Saleh (2004) e Hexsel (2002) defendem que o software livre apresenta vantagens, desvantagens e, principalmente, desvantagens imaginárias que não se sustentam, resumidas na Tabela 2 .

Hexsel (2002) aponta ainda algumas características chamando-as de desvantagens imaginárias, pois mesmo aplicativos com fins comerciais utilizam licenças com cláusulas em que o proprietário se exime de qualquer responsabilidade por danos ou prejuízos, relata a prestação de suporte 24 horas por dia também por empresas prestadoras de serviços em software livre e que muitos sistemas comerciais são estáveis e rodam sobre software livre.

\section{Metodologia da pesquisa}

Devido aos problemas e objetivos gerais e específicos da pesquisa "adoção, seleção e implantação de ERP Livre”, métodos qualitativos inicialmente mostram-se mais aderentes à busca da resolução do problema desta pesquisa, uma vez que, segundo Bryman (1989), a pesquisa qualitativa tem as seguintes características:

- 0 pesquisador observa os fatos sob a ótica de alguém interno à organização;

- A pesquisa busca uma profunda compreensão do contexto da situação;

- A pesquisa enfatiza o processo dos acontecimentos, isto é, a sequência dos fatos ao longo do tempo;

- 0 enfoque da pesquisa é mais desestruturado, não há hipóteses fortes no início da pesquisa. Isso confere à pesquisa bastante flexibilidade;

- A pesquisa emprega mais de uma fonte de dados.

Serapioni (2000) acrescenta mais uma característica importante:

- A pesquisa tende a ser holística e pouco generalizável devido às peculiaridades do contexto.

Dentro do universo qualitativo, necessita-se da definição do método a ser utilizado. Para Nakano \& Fleury (1996), os três principais métodos qualitativos aplicados na área de engenharia de produção são:

Tabela 2. Vantagens, desvantagens e desvantagens hipotéticas do software livre.

\begin{tabular}{|c|c|c|}
\hline Vantagens & Desvantagens & Desvantagens imaginárias \\
\hline Baixo Custo Econômico & Instalação e configuração difíceis & Ausência de proprietário ou responsável legal \\
\hline Baixo Custo Social & Interface não padronizada & Inexistência de suporte por meio do modelo tradicional \\
\hline Independência de tecnologia proprietária & Mão de obra escassa & Instabilidade \\
\hline Independência de fornecedor único & & Poucos aplicativos comerciais \\
\hline \multicolumn{3}{|l|}{ Robustez } \\
\hline \multicolumn{3}{|l|}{ Garantia contra descontinuidade } \\
\hline \multicolumn{3}{|l|}{ Personalização } \\
\hline Não obsolescência do hardware & & \\
\hline
\end{tabular}


a pesquisa-ação, a pesquisa participante e o estudo de caso. Inicialmente o método que pareceu ao autor mais adequado às respostas da pesquisa foi o estudo de casos múltiplos, contudo, devido à insipiência do tema, aos raros casos reais de aplicação de ERP livres no Brasil e à dificuldade de acesso aprofundado para estudo detalhado em um destes casos, o método de estudo de caso poderia ter os resultados de sua aplicação comprometida.

Paralelamente, em função de seus estudos e artigos, o autor foi convidado na universidade a atuar em um projeto de campo para adoção, seleção e implantação de um ERP livre em uma organização filantrópica. A pesquisa-ação e a pesquisa participativa são muito similares, segundo Durscki (2007). Assim, o autor avaliou a aderência do método pesquisa-ação para apoiar a busca das respostas às questões desta pesquisa.

A pesquisa-ação, segundo Paul Coughlan e David Coghlan (Coughlan \& Coghlan, 2002), pode ser definida por quatro características principais:

- Pesquisa em ação, mais que pesquisa sobre ação - Usa abordagem científica para estudar a solução de um problema, através de um processo de quatro passos cíclicos: Planejar, tomar ação, avaliar a ação e refazer o planejamento.

- Participativa - Membros estudados participam ativamente do processo anteriormente citado.

- Concorrente com ação - Meta é fazer a ação mais efetiva enquanto constrói o conhecimento científico.

- Uma sequência de eventos e uma abordagem para resolver um problema.
Assim, as questões desta pesquisa, que busca avaliar como adotar e como selecionar e implementar um ERP livre, são altamente aderentes ao uso da pesquisa-ação, conforme as características apresentadas por Paul Coughlan e David Coghlan (Coughlan \& Coghlan, 2002) anteriormente citado, e este será o método utilizado no decorrer desta pesquisa.

\subsection{Delineamento da pesquisa: \\ Planejamento da pesquisa-ação}

0 planejamento da pesquisa-ação envolve 5 etapas e 2 características, conforme interpretação gráfica apresentada na Figura 2.

As etapas estão descritas a seguir:

E1 - Introdução: Definiu-se o tópico 1 deste artigo, no qual o principal problema é descrito, como: Como adotar e selecionar um ERP livre? Como implementar um ERP livre? 0 objetivo geral deste trabalho é compreender e avaliar o processo de adoção, seleção e implantação de ERP livre.

E2 - Fundamentação Teórica: Os principais conceitos que envolvem o tema são sistemas ERP e software livre apresentados no tópico 2 de fundamentação teórica deste trabalho; estudos sobre o método de pesquisa-ação e as suas formas de aplicação também deram base para o desenvolvimento da pesquisa.

E3 - Elaboração do modelo inicial: Neste trabalho, o modelo inicial proposto trata de ciclo de vida de um ERP livre, com foco nos estágios de adoção, seleção e implantação e é apresentado no tópico 5.

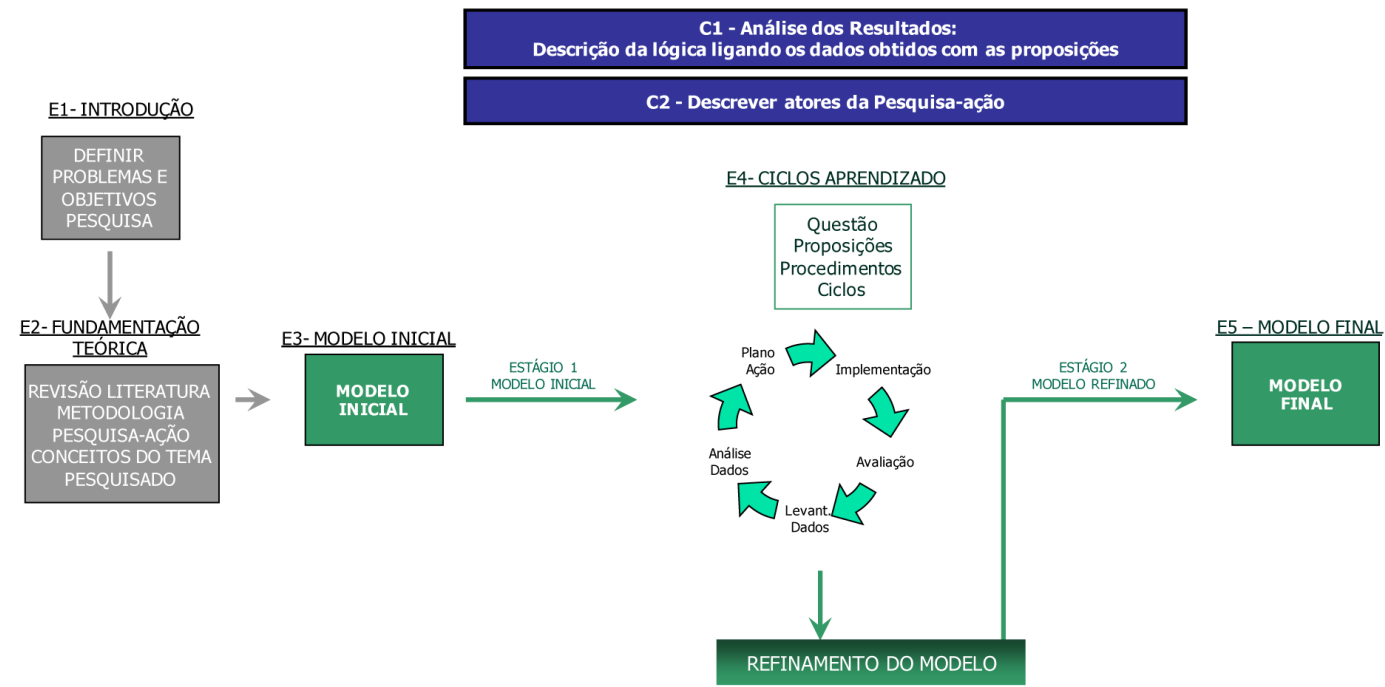

Figura 2. Planejamento da pesquisa-ação. Fonte: Baseado em Coughlan \& Coghlan (2002), Yin (2002) e Durscki (2007). 
E4 - Ciclos da pesquisa-ação: Foram definidos 2 ciclos para este estudo: o $1^{\circ}$ ciclo se refere aos estágios de adoção e seleção de um ERP livre; o $2^{\circ}$ ciclo se refere à implantação de um ERP livre. Estes ciclos foram definidos em concordância com o modelo inicial apresentado no tópico 5.

- Questões $1^{\circ}$ ciclo: A fim de dirigir a realização do $1^{\circ}$ ciclo de aprendizado deste trabalho, as seguintes questões relativas ao estágio de adoção e seleção do ERP, elaboradas com base no objetivo da pesquisa.

- Porque adotar um ERP livre?

- Como é o processo de adoção e seleção do ERP livre?

- Proposições $1^{\circ}$ ciclo: Em consonância com as questões do $1^{\circ}$ ciclo, colocam-se as seguintes proposições relativas à adoção e seleção do ERP:

- As necessidades e fatores de decisão que levam à adoção de um ERP independem se o mesmo é proprietário ou desenvolvido sob o modelo do software livre;

- 0 custo de aquisição inicial pode ser um fator de decisão para adoção de um ERP livre;

- Os processos de seleção de um ERP livre seguem os mesmos métodos e procedimentos de um ERP proprietário.

- Procedimentos de roteiro de pesquisa e coleta de dados do $1^{\circ}$ ciclo: Utilizam-se neste ciclo, primariamente, anotações de observação e participação direta do pesquisador no processo de adoção e seleção do ERP. Quando as observações não forem consideradas suficientes, entrevistas não estruturadas deverão ser realizadas com os principais participantes dos respectivos processos e um questionário utilizado para coleta de dados, com perguntas abertas constando as anotações e respostas do pesquisador.

- Quais os objetivos estratégicos, visões, metas e objetivos da instituição?

- Quais os fatores críticos de sucesso para a instituição?

- Qual a visão de importância estratégica da T1 para os objetivos da corporação?

- Que sistemas de gestão são desejados para atender às estratégias da corporação?

- Por que a empresa optou por um sistema ERP? Quais os benefícios buscados com o ERP?

- Por que foi adotado um ERP desenvolvido na forma de software livre?
- Quais seriam as possíveis alternativas ao uso de um ERP, e por que foram preteridas?

- Quais as principais características dos sistemas anteriores?

- Quais os benefícios buscados pela empresa ao utilizar o sistema ERP? Eles foram formalmente definidos no início do projeto?

- Como foi o processo de tomada de decisão e de escolha do ERP? Quais foram às etapas? Quem foi envolvido?

- Quais foram os fatores considerados para comparação das alternativas de seleção de ERP?

- A empresa tem alguma característica particular que poderia representar uma dificuldade na utilização do ERP?

- Questões 20 ciclo: A fim de dirigir a realização do $2^{\circ}$ ciclo de aprendizado deste trabalho, as seguintes questões relativas à implantação do ERP foramelaboradas com base no objetivo da pesquisa.

- Como foi o processo de implantação do ERP livre?

- Houve dificuldades do uso de um modelo de implantação de um ERP proprietário para o ERP livre?

- 0 mesmo é aderente ao ERP livre?

- Proposições $2^{\circ}$ ciclo: Em consonância com as questões do $2^{\circ}$ ciclo, colocam-se as seguintes proposições relativas à adoção e seleção:

- Um ERP livre pode se implementar com o mesmo método, dificuldades e procedimentos de um ERP proprietário.

- Procedimentos de roteiro de pesquisa e coleta de dados do $2^{\circ}$ ciclo: Utilizam-se neste ciclo, primariamente, anotações de observação e participação direta do pesquisador no processo de implantação do ERP. Quando as observações não forem consideradas suficientes, entrevistas não estruturadas deverão ser realizadas com os principais participantes dos respectivos processos e um questionário utilizado para coleta de dados, com perguntas abertas constando as anotações e respostas do pesquisador.

- Como foi conduzida a implantação do ERP? Quem definiu a metodologia? Qual era esta metodologia?

- Como foi estruturada a equipe de projeto?

- Que problemas ocorreram durante a implantação? Como foram resolvidos? 
- Quando surgia uma discrepância entre o sistema e os processos do departamento como era resolvida? Se a alternativa fosse mudar o processo, como isto era conduzido?

- Quais foram os aspectos considerados críticos durante a fase de implantação?

- Como foi o início da operação? Houve "paralelo" com o sistema antigo e outras ferramentas de apoio (como as planilhas Excel, por exemplo)?

E5 - Elaboração do modelo final: 0 modelo final após o refinamento resultante da aplicação dos ciclos da pesquisa-ação encontra-se no tópico 6 .

Apresenta-se a seguir a descrição das 2 características do modelo de planejamento da pesquisa-ação, conforme se verifica na Figura 2:

C1 - Descrever atores da pesquisa-ação: No caso específico do projeto desta pesquisa os atores são:

- Autor/Pesquisador: Líder e relator da pesquisa. No projeto, atuou como gerente de projetos e consultor funcional nos processos de adoção, seleção e implantação do ERP. Teve participação ativa nas avaliações resultantes da aplicação de todos os ciclos da pesquisa-ação deste trabalho.

- CEO: Presidente e fundador da organização, responsável por aprovar qualquer investimento financeiro no projeto; responsável pelas questões estratégicas. Teve forte atuação e poder de decisão nos processos de adoção e seleção do ERP, com menor participação no processo de implantação.

- Analista de Negócios: Gerente da instituição responsável pela operação da empresa; responsável por definir os processos da empresa e a análise da aderência ao sistema ERP. Nesta pesquisa, teve forte atuação e influência nos processos operacionais voltados à implantação do sistema.
- Analistas Técnicos: 2 desenvolvedores contratados pela instituição junto a uma empresa de consultoria responsável pela customização do sistema, sem influência direta nos processos.

C2 - Análise dos resultados: Descrição da lógica ligando os dados obtidos com as proposições: Neste trabalho, a análise dos resultados será realizada através de conclusões resultantes da observação do autor-pesquisador apresentadas no final deste artigo.

\section{0 modelo inicial}

Considerando a proposta do avaliar aspectos da adoção, seleção e implantação de ERP livre, desenvolveu-se um modelo inicial de ciclo de vida para que fosse refinado ao longo do processo de pesquisa de forma interativa como característica inerente do método aplicado. Algumas dezenas de modelos de ciclo de vida podem ser encontradas na literatura, algumas inclusive refinadas e submetidas a trabalhos de campo, como as propostas de Souza \& Zwicker (2001) e de Silva et al. (2005). Entretanto nenhum modelo de ciclo de vida encontrado na literatura considerou alguma particularidade diante da utilização de sistemas ERP desenvolvidos na forma de software livre.

Assim, a concepção do modelo inicial proposto neste trabalho considera não haver distinções entre o modelo de um ERP proprietário ou livre e foi posteriormente refinado através da pesquisa-ação. Este modelo é composto por etapas e atividades. Podemos ver as etapas consideradas no modelo conforme Figura 3.

- Decisão de adoção e seleção: Etapa inicial em que se decide por implementar um sistema ERP e realiza-se a seleção da consultoria de implantação e fornecedor do software.

- Implantação: Etapa em que se entende o processo e as funcionalidades do software de cada módulo a

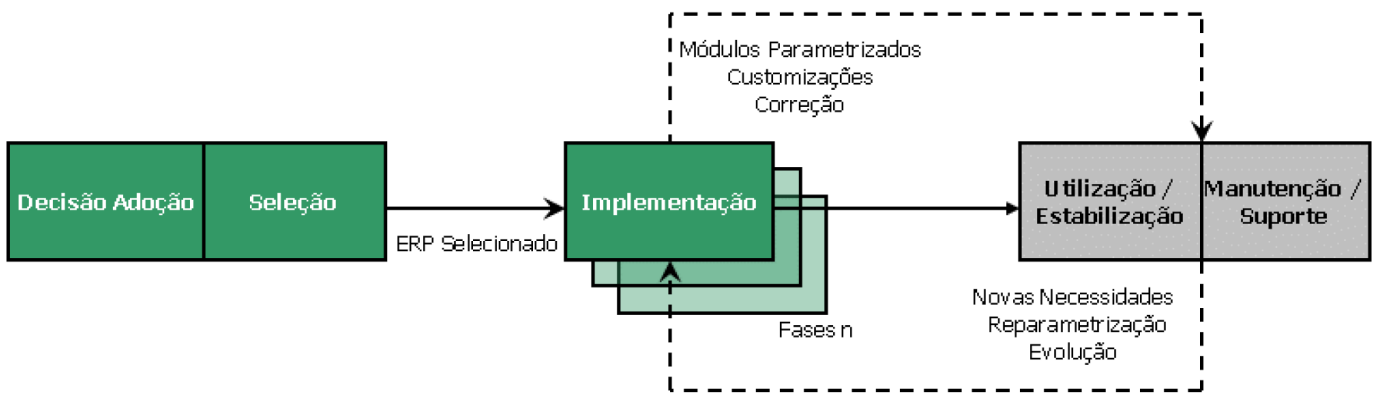

Figura 3. Etapas do modelo inicial de ciclo de vida de um ERP livre e proprietário. Fonte: Adaptado de Souza \& Zwicker (2001) e Silva et al. (2005). 
ser implantado, identificar as discrepâncias e decidir mudanças em procedimentos, parametrizações do sistema, cadastros e migrações de dados e customizações para atendimento do processo. Como saída deste estágio, temos os usuários treinados, os dados migrados e cadastrados e os módulos adaptados e customizados, iniciando o uso do sistema por parte dos usuários.

- Estabilização/Utilização/Manutenção/Suporte: Uma vez o módulo adaptado e os usuários treinados, inicia-se o estágio de estabilização do sistema, no qual correções de parametrizações, de cadastros, mudanças de processos podem ser necessárias; passa também pelo suporte e evoluções adaptativas e corretivas que podem levar a novas adaptações do software, realimentando a volta para o estágio anterior conforme representado na linha pontilhada da Figura 3.

Uma vez definidas às etapas do modelo inicial de ciclo de vida na Figura 3, realiza-se a "explosão" de cada uma das respectivas etapas com a finalidade de detalhar as atividades realizadas em cada uma delas, completando o modelo de ciclo de vida representado na Figura 4.

A seguir, na Figura 5, são apresentadas as atividades da etapa de implantação de um ERP.
Ressalta-se que, apesar de o modelo inicial conter as atividades da etapa de utilização/estabilização e manutenção/suporte, esta etapa, detalhada na Figura 6, não foi objeto da pesquisa-ação, não sendo, portanto, refinada no trabalho de campo.

\section{Trabalho de campo}

Neste tópico, detalha-se o trabalho de campo que suportou a pesquisa-ação e os resultados deste trabalho.

\subsection{O Portal da Ajuda}

Visando refinar o modelo inicial, implementou-se um ERP livre no Portal da Ajuda seguindo o planejamento da pesquisa-ação da Figura 2. 0 Portal da Ajuda (2008) é uma ONG (Organização não Governamental) criada em 24 de março de 2003, com o objetivo de identificar instituições, suas necessidades e operacionalizar através da Internet a busca de potenciais doadores, num raio de $50 \mathrm{Km}$ da Praça da Sé, na Capital do Estado de São Paulo, sempre com o apoio técnico de assistentes sociais.

0 Portal da Ajuda funciona como um "ator intermediário entre os doadores e instituições demandantes, sendo responsável pela transferência

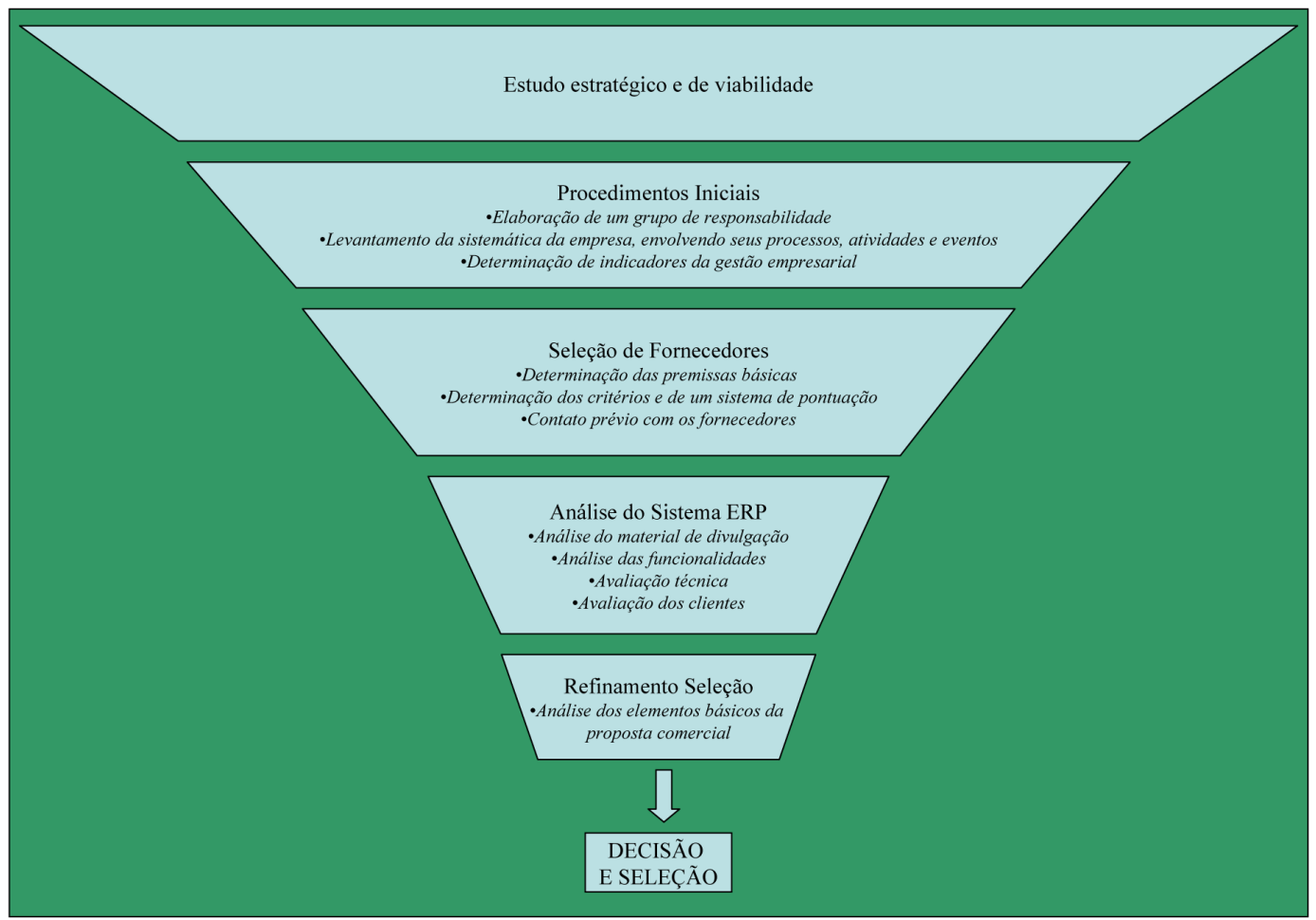

Figura 4. Atividades da etapa de adoção e seleção de um ERP. Fonte: Adaptado de Spinola et al. (2004) e Tonini (2003). 
de bens duráveis ociosos de empresas e pessoas para instituições que necessitam destes bens".

\subsection{Aplicação do modelo inicial (fase adoção e seleção) - Execução do $1^{\circ}$ Ciclo da Pesquisa Ação}

Assim, neste tópico, aplica-se o modelo inicial proposto (fase adoção e seleção) que é refinado através do planejamento da pesquisa-ação com a finalidade, do ponto de vista da pesquisa, de responder às questões e proposições consideradas na fase de planejamento da Pesquisa Ação no $1^{\circ}$ ciclo apresentadas na Tabela 3.

Depois da aplicação do modelo inicial proposto para obter as respostas e avaliações do planejamento da pesquisa-ação proposto na Figura 2, os seguintes resultados foram alcançados.
- Por que adotar um ERP livre?

Avaliou-se na execução do $1^{\circ}$ ciclo de planejamento da pesquisa-ação que os principais fatores e características que levaram à adoção de um ERP livre em detrimento de um proprietário neste estudo de caso foram:

- Pouco uso dos processos prontos "Melhores Práticas" dos sistemas ERP: Nos sistemas ERP proprietários, em consequência de anos de evolução e amadurecimento, existe imensa quantidade de processos com as "melhores práticas” disponíveis para as empresas se adaptarem, usado inclusive como fundamento para o alto custo da aquisição de suas licenças. Nos sistemas ERP livres avaliados, diante do estágio de evolução, verificou-se somente que os processos básicos estavam disponíveis, como pedidos de compra, vendas, estoques, recebimentos, contabilização, entre outros.

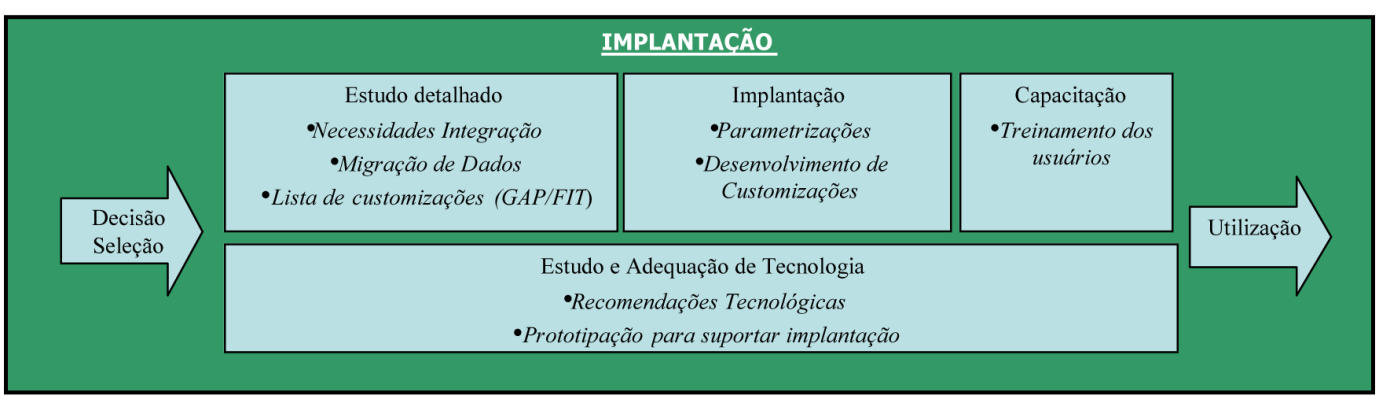

Figura 5. Atividades da etapa de implantação de um ERP. Fonte: Adaptado de Souza \& Zwicker (2001) e Silva et al. (2005).

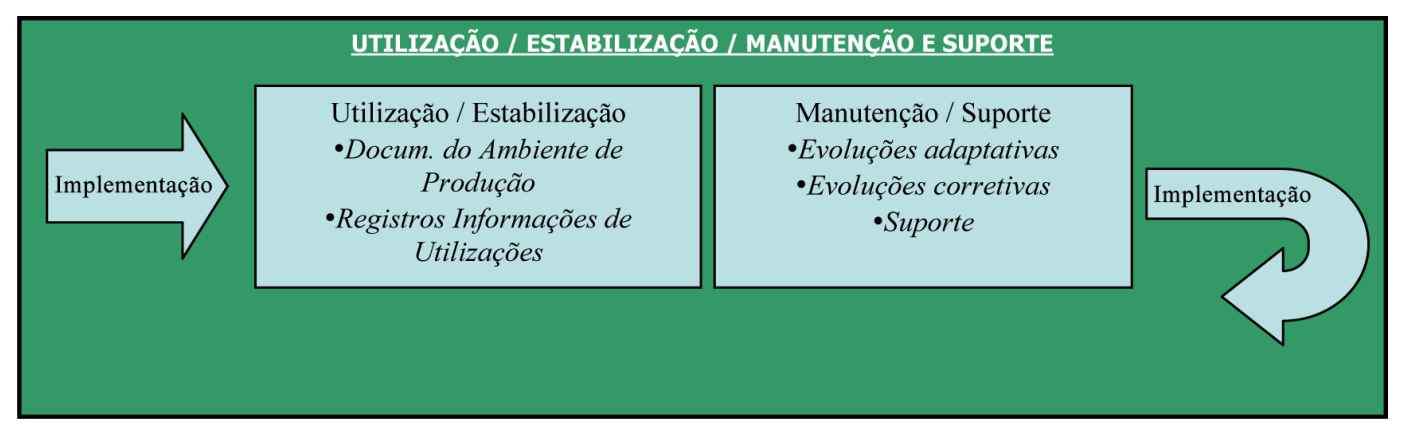

Figura 6. Atividades da etapa de utilização e manutenção de um ERP. Fonte: Adaptado de Souza \& Zwicker (2001) e Silva et al. (2005).

Tabela 3. Tabela com questões e proposições do $1^{\circ}$ ciclo da Pesquisa Ação.

\begin{tabular}{ll}
\hline \multicolumn{1}{c}{ Questões 1 Ciclo } & \multicolumn{1}{c}{ Proposições 1 Ciclo } \\
\hline & - As necessidades e fatores de decisão que levam à adoção de um \\
- Por que adotar um ERP livre? & ERP independem se o mesmo é proprietário ou desenvolvido sob o \\
& modelo do software livre; \\
- Como foi o processo de adoção e seleção do ERP Livre? & - 0 custo de aquisição inicial pode ser um fator de decisão para \\
& adoção de um ERP livre; \\
& - Os processos de seleção de um ERP livre seguem os mesmos \\
& métodos e procedimentos de um ERP proprietário. \\
\hline
\end{tabular}


Estes processos são utilizados normalmente por qualquer natureza e tamanho de empresa, com pequenas ou nenhuma adaptação, e este foi o caso do Portal da Ajuda.

- Uso de uma Ferramenta com Modelo Estruturado Pronto para customizações: Os dois sistemas ERP disponibilizavam modelos estruturados para desenvolvimento. As Ferramentas com Modelos Estruturados proprietários normalmente usavam linguagens proprietárias e próprias (ex. ABAP-SAP, FORMS-ORACLE, etc.) e os livres usavam linguagens abertas (ex. JAVA, PHP, etc.), mas os dois atendem às necessidades de personalização do software no projeto do Portal da Ajuda. A questão é que com o software livre foi possível usar uma ferramenta com baixo custo de aquisição inicial.

- Baixo custo de aquisição inicial: 0 alto custo de aquisição inicial dos sistemas ERP proprietários pode se tornar uma barreira para sua adoção pelas pequenas e médias organizações, como foi o caso do Portal da Ajuda.

- Opção ao desenvolvimento interno: Em algumas pequenas corporações, verifica-se o uso de desenvolvimento interno. 0 uso de uma Ferramenta com um Modelo Estruturado para personalização, o baixo custo inicial e o uso de funcionalidades básicas tornaram o ERP livre uma boa opção ao desenvolvimento interno no Portal da Ajuda.

- Independência de plataforma tecnológica: 0 ERP livre possibilita o uso de sistemas de software complementares livres ou proprietários com total independência de escolha de plataforma tecnológica. No caso do Portal da Ajuda, diante do ERP livre Compiere escolhido, foi aberta a possibilidade de uso de sistema operacional LINUX e do banco de dados Postgree. Em função de a organização ter recebido como doação as licenças proprietárias dos fornecedores e da restrita disponibilidade e acesso a pessoal especializado nestas plataformas abertas, optou-se pela plataforma Windows Server 2003 e banco de dados proprietário Oracle Enterprise Edition.

- Escalabilidade: Um dos problemas notados em empresas que optam pelo desenvolvimento interno são restrições futuras apresentadas diante do crescimento destas empresas, normalmente por limitações tecnológicas e restrições inerentes ao desenvolvimento inicial. Tanto o ERP proprietário quanto o livre normalmente não limitam este crescimento futuro das empresas.

- Acesso WEB: Alguns sistemas ERP proprietários e a maioria dos sistemas ERP livres pesquisados permitiam o acesso à WEB. A diferença é que os proprietários usavam linguagem própria, e, consequentemente, necessitavam de software servidor WEB proprietários. 0 sistema ERP aberto, por normalmente usar o estado da arte da tecnologia, já é escrito nativamente por linguagens WEB, como JAVA e PHP, o que possibilita o uso de servidores WEB livres e de mercado, como o APACHE, por exemplo.

A segunda questão foi:

- Como é o processo de adoção e seleção do ERP livre?

Avaliou-se na execução do $1^{\circ}$ ciclo de planejamento da pesquisa-ação que o processo de adoção e seleção de ERP livre não tinha sido estudado por nenhum modelo de ciclo de vida apresentado. 0 processo de adoção precisou avaliar características como as descritas na questão anterior de "por que adotar um ERP livre”. Já a seleção precisou de um estudo na literatura, principalmente em Campos (2006), Saleh (2004) e Herzog (2006), para modificar as atividades de seleção. A principal alteração foi a inclusão de um procedimento para mapeamento dos sistemas ERP livres (Correa et al., 2008a, b) com busca em bases de dados secundárias como sites repositórios e sites oficiais destes sistemas.

A comparação para seleção de ERP, apresentando possibilidade de competidores que podem ser sistemas ERP livres ou proprietários ou os dois, foi mantida no modelo final, mas não foi utilizada plenamente no projeto do Portal da Ajuda, uma vez que um ERP livre já foi decidido na etapa anterior da pesquisa.

Já na avaliação das proposições podemos considerar:

- As necessidades e fatores de decisão que levam à adoção de um ERP independem se ele é proprietário ou desenvolvido sob o modelo do software livre.

Avaliação: No caso estudado, as necessidades e fatores que levaram à adoção de um ERP mostraram algumas características que independem da forma de seu desenvolvimento (se é livre ou proprietário) e algumas características particulares críticas para a determinação de um ERP livre. Algumas necessidades como funcionalidades orientadas a processos (recebimentos, compras, vendas, entre outros) e acesso de múltiplos usuários e via WEB levam à decisão de adoção de um ERP independentemente de ser livre ou proprietário. A eliminação de redundâncias de informações com o uso de uma base de dados centralizada também apoia esta decisão.

Entretanto, o alto grau de particularização necessário em projetos como o Portal da Ajuda (customização), o pequeno uso das chamadas "melhores práticas" presentes no ERP proprietário e o alto custo de 
aquisição inicial restringem a decisão por um ERP proprietário. Assim, os fatores de decisão que levam a um ERP proprietário ou livre podem apresentar características particulares com base no estudo de campo realizado.

- 0 custo de aquisição inicial pode ser um fator de decisão para adoção de um ERP livre.

Avaliação: Sim, neste estudo de campo, o custo mostrou-se um fator de decisão, mas outros aspectos também influenciaram igualmente na adoção de um ERP Livre como:

- Pouco uso das melhores práticas;

- Necessidade de uma ferramenta com modelo estruturado pronto para desenvolvimento;

- Escalabilidade;

- Opção ao desenvolvimento interno.

- Os processos de seleção de um ERP livre seguem os mesmos métodos e procedimentos de um ERP proprietário.

Avaliação: A fase de adoção e seleção tem atividades particularizadas normalmente não consideradas nos métodos e procedimentos de um ERP proprietário, principalmente as atividades referentes ao mapeamento dos sistemas ERP livres, uma vez que o modelo de negócios desta forma de desenvolvimento livre é baseado em serviços e não na aquisição de licenças.

\subsection{Aplicação do modelo inicial (fase implantação) - Execução do $2^{\circ}$ Ciclo da Pesquisa Ação}

Assim, neste tópico, aplica-se o modelo inicial proposto (fase implantação) que é refinado através da pesquisa-ação com a finalidade, do ponto de vista da pesquisa, de responder às questões e proposições consideradas na fase de planejamento da Pesquisa Ação no $2^{\circ}$ ciclo apresentados na Tabela 4.

Tabela 4. Tabela com questões e proposições do $2^{\circ}$ ciclo da Pesquisa Ação.

\begin{tabular}{ll}
\hline \multicolumn{1}{c}{ Questões 2 Ciclo } & \multicolumn{1}{c}{ Proposições 2 Ciclo } \\
\hline - Como foi o processo de & - Um ERP livre pode ser \\
implementação do ERP Livre? & $\begin{array}{l}\text { implementado com o mesmo } \\
\text { método, dificuldades e } \\
\text { procedimentos de um ERP } \\
\text { proprietário. }\end{array}$ \\
- Houve dificuldades do uso de & \\
um modelo de implementação & \\
de um ERP proprietário para o & \\
ERP livre? & \\
- O mesmo é aderente ao ERP & \\
livre? & \\
\hline
\end{tabular}

Depois da aplicação do modelo inicial (fase implantação) proposto para obter as respostas e avaliações do planejamento da pesquisa-ação proposto na Figura 2, os seguintes resultados foram alcançados.

Questões do $2^{\circ}$ ciclo

As questões levantadas no planejamento do $1^{\circ}$ ciclo da pesquisa-ação apresentados na Tabela 4 foram:

- Como é o processo de implantação de um ERP livre?

Avaliou-se na execução do $2^{\circ}$ ciclo de planejamento da pesquisa-ação que as etapas e atividades de implantação são as mesmas de um ERP proprietário.

Há dificuldades do uso de um modelo de implantação de um ERP proprietário para o ERP livre? 0 mesmo é aderente ao ERP livre?

Não houve dificuldades especificamente sobre o modelo, que continha as fases e atividades executadas na implantação do ERP livre, sem distinções quanto a um ERP proprietário. A implantação do ERP livre apresentou maiores dificuldades principalmente na contratação de serviços externos com restrições sobre a raridade e a imaturidade de profissionais que trabalham sobre o sistema ERP livre escolhido.

Já na avaliação das proposições, podemos considerar:

- Um ERP livre pode se implementar com o mesmo método, dificuldades e procedimentos de um ERP proprietário.

Avaliação: Utilizaram-se para a implantação do ERP livre métodos e procedimentos usados para um ERP proprietário conforme o modelo inicial proposto na implantação. 0 modelo e os procedimentos mostraram-se adequados à implantação de um ERP livre. Em contrapartida, dificuldades particulares da implantação do Portal da Ajuda foram detectadas como:

- Falta de profissionais qualificados com conhecimento do ERP livre selecionado no mercado;

- Profissionais que trabalham com software livre com perfil muito técnico, sem conhecimento de processos de negócios;

- Desinteresse dos profissionais em se capacitarem com sistemas pouco conhecidos no mercado;

- Existência de poucas empresas de consultoria que implementam o sistema ERP livre escolhido;

- Custo de serviços (implantação, suporte, etc.) similares a de qualquer outro ERP proprietário;

- Alocação (filantropicamente, por uma empresa parceira) de um profissional estagiário no projeto, reduzindo a eficiência do projeto que necessitava de um desenvolvedor experiente; 
- Restrição de tempo do pesquisador, por trabalhar em empresa privada e realizar estudos na USP, sem a dedicação recomendada para um consultor que implementa estes sistemas.

No próximo tópico, avaliam-se, de acordo com o planejamento da pesquisa-ação, as características da adoção, seleção e implantação do ERP livre.

\subsection{Características especiais da adoção, seleção e implantação de ERP Livre}

Com a conclusão dos ciclos da pesquisa-ação, este tópico tem como objetivo apresentar uma tabela resumida das principais características especiais dos processos de adoção, seleção e a implantação de um ERP livre, conforme se apresenta na Tabela 5 .

Verifica-se que as características especiais do processo de adoção, seleção e implantação do ERP livre, até mesmo pelo atual estágio de maturidade deste modelo de software no país, são relevantes e devem ser consideradas para a adoção de um sistema nesse modelo de desenvolvimento.

\section{0 modelo final}

Considerando a proposta do avaliar aspectos da adoção, seleção e implantação de ERP livre, apresenta-se neste tópico um modelo final de ciclo de vida refinado ao longo do processo de pesquisa interativo.

Verificamos que o modelo inicial proposto na Figura 3 que contempla as etapas de adoção, seleção e implantação de um ERP independe de este ser livre ou proprietário. Já nas atividades detalhadas para a fase de adoção e seleção da Figura 4, o modelo refinado pelo autor propõe alterações conforme mostrado na Figura 7, destacando:

Tabela 5. Características especiais das etapas de adoção, seleção e implantação de ERP livre.

\begin{tabular}{|c|c|}
\hline Etapa & Características Especiais do ERP Livre \\
\hline Adoção & $\begin{array}{l}\text { - Projetos de alto grau de particularização com pouco uso das funcionalidades “melhores práticas” compradas em um ERP } \\
\text { proprietário devem avaliar a adoção de um ERP livre. } \\
\text { - Uso do estado da arte da tecnologia em função de terem desenvolvimentos recentes e sem base instalada em tecnologias } \\
\text { antigas que evitem uma migração. } \\
\text { - Independência tecnológica de escolha de Sistema Operacional, Banco de dados, Servidor WEB, entre outros em função da } \\
\text { natureza "livre" de desenvolvimento, sem fidelização forçada dos clientes. } \\
\text { - Baixo custo de aquisição inicial, que permite a pequenas empresas aderirem ao sistema ERP e crescerem junto com o } \\
\text { software. } \\
\text { - Opção melhor que um desenvolvimento interno do zero, com funcionalidades prontas dos principais processos e com } \\
\text { Ferramenta para Desenvolvimento pronto para padronizar. }\end{array}$ \\
\hline Seleção & $\begin{array}{l}\text { - Difícil mapeamento, uma vez que estes ainda não possuem apelo mercadológico no Brasil e pesquisas a sites repositórios } \\
\text { são necessárias. Sites repositórios são locais onde a comunidade interage e o software encontra-se disponível para } \\
\text { download. } \\
\text { - Inexistência de sistemas com funcionalidades globais (multiempresa, multilinguas e moedas) que apresentem a } \\
\text { localização às necessidades tributárias e fiscais do Brasil. Ex. Dos sistemas ERP livres mapeados com características } \\
\text { globais, somente } 2 \text { apresentavam localização Brasil, e nenhum apresentava estas funcionalidades disponiveis na } \\
\text { distribuição original do software. } \\
\text { - Falta de transparência e imaturidade jurídica sobre ERP livre no Brasil: A localização Brasil nos casos encontrados foi } \\
\text { tratada de forma “proprietária” pelas consultorias que a desenvolveram, que não esclareciam em seus sites ou material de } \\
\text { divulgação a forma de licenciamento deste desenvolvimento “adicional”. } \\
\text { - Poucas consultorias especializadas nestes softwares foram encontradas no Brasil e muitos desenvolvedores técnicos de } \\
\text { software apresentando-se como empresas de implantação de ERP. Ex: Somente } 5 \text { consultorias foram encontradas para } \\
\text { implantação dos sistemas Adempiere e Compiere (Megawork, TKTl, Visuelles, Kenos e Conceptia). Em contrapartida, não } \\
\text { foram poucos os recém-formados em cursos de computação que se apresentaram como empresas de consultoria ERP. } \\
\text { - Falta de um modelo de desenvolvimento colaborativo e sustentável do ERP livre no Brasil: Nenhuma atividade de } \\
\text { desenvolvimento, estratégia ou evolução colaborativa do ERP livre foi encontrado entre as empresas, que apresentaram } \\
\text { somente uma reação de competição em um modelo não completamente maduro. lncertezas e falta de transparência } \\
\text { sobre as adaptações desenvolvidas para atender às necessidades brasileiras só vêm a enfraquecer a seleção/adoção do ERP } \\
\text { Livre. }\end{array}$ \\
\hline Implementação & $\begin{array}{l}\text { - Falta de profissionais qualificados com conhecimento do ERP livre selecionado no mercado. } \\
\text { - Profissionais que trabalham com software livre apresentaram perfil muito técnico sem conhecimento de processos ou } \\
\text { negócios, apesar de frequentemente atestarem possuir tais habilidades. } \\
\text { - Desinteresse dos profissionais em se capacitarem com sistemas de pouco apelo mercadológico. } \\
\text { - Custo de serviços (implantação, suporte, etc.) similar ao de qualquer outro ERP proprietário, mitigando as economias } \\
\text { iniciais de aquisição. Ex: Em orçamento realizado para novos desenvolvimentos com } 3 \text { empresas, o valor do homem- } \\
\text { hora apresentado nas propostas era de valor similar ao de ERP proprietários, conhecidos pelo autor não em função deste } \\
\text { trabalho, mas em razão de este trabalhar e realizar estas propostas em um ERP proprietário. } \\
\text { - Profissionais sem a experiência necessária, recém-formados nas cadeiras de cursos de computação se apresentando como } \\
\text { especialistas em implantação ERP. }\end{array}$ \\
\hline
\end{tabular}




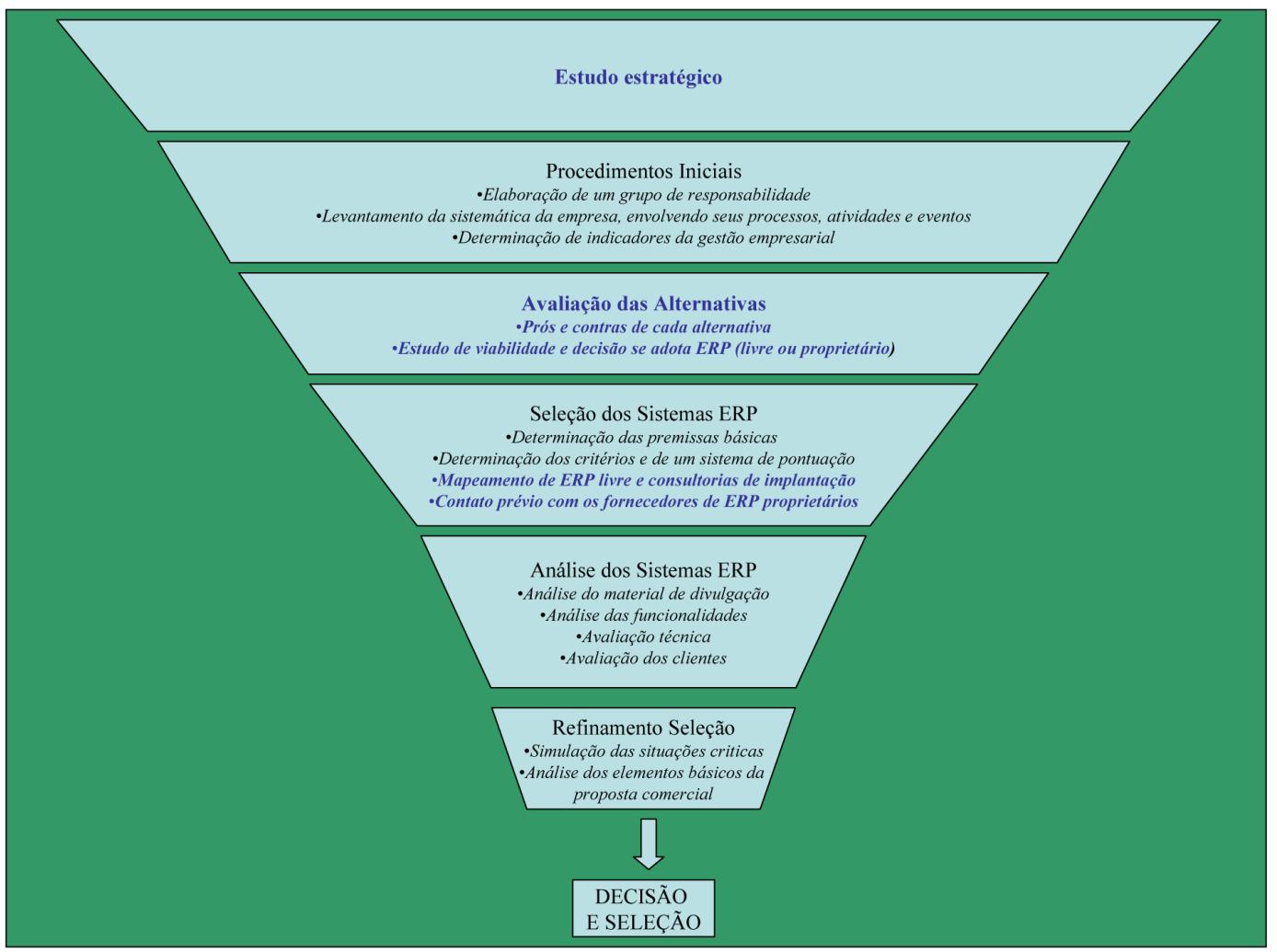

Figura 7. Atividades da etapa de adoção e seleção de um ERP. Fonte: Adaptado de Spinola et al. (2004) e Tonini (2003).

- Estudo estratégico: Pequenas alterações diante do modelo inicial no que se refere à análise de viabilidade que foi modificada para atividade posterior.

- Avaliação de Alternativas: Alterações no Modelo Inicial com a inserção de 2 novas atividades, uma com a finalidade de avaliação de alternativas ao uso do ERP e outra sobre o estudo de viabilidade das alternativas para atendimento das necessidades da empresa.

- Seleção dos Sistemas ERP: Alterações no Modelo Inicial com a inserção de uma nova atividade de "mapeamento de ERP livres e consultorias de implantação" para habilitar a participação de sistemas ERP livres na comparação. 0 título "Seleção de Fornecedores ERP" foi alterado para "Seleção de Sistemas ERP”. Esta denominação representa melhor um modelo que pretende atender a sistemas ERP proprietários e livres, uma vez que o modelo de negócios de sistemas ERP livres é baseado em serviços, e não na venda de licenças.

Já no detalhamento de implantação da Figura 5, as atividades propostas para sistemas ERP proprietários mostraram-se aptas também para um ERP livre.

Não houve no planejamento da pesquisa-ação realizada nenhum ciclo para refinar as atividades referentes à etapa de utilização, estabilização, suporte e manutenção.

\section{Conclusões}

0 objetivo inicial de "Compreender e avaliar o processo de adoção, seleção e implantação de ERP Livre" foi atingido. Os objetivos específicos de "Propor, aprimorar e aperfeiçoar um modelo de ciclo de vida para ERP (livre e proprietário)" e "Identificar e discutir características especiais dos processos de adoção, seleção e implantação de ERP livre" também foram atingidos, conforme o modelo final apresentado no tópico 6 e as características especiais apresentadas na Tabela 5 .

ERP livres adaptados a questões locais, legais, fiscais e contábeis brasileiras não foram encontrados em nenhuma distribuição oficial nesta pesquisa. No estudo realizado, encontraram-se ERP livres que foram alterados da sua fonte oficial por empresas brasileiras para contemplar as questões locais fiscais e contábeis locais, mas sem especificação da forma de licenciamento e legalidade destas versões como software livre. A imaturidade jurídica brasileira também é importante fator a se avaliar na adoção de um ERP livre. 
Como conclusões resultantes deste trabalho, apresentam-se fatores críticos que podem apoiar as empresas na avaliação para a adoção, seleção e implantação de um ERP livre:

- Empresas com necessidade de sistemas com características de ERP, conforme descritos na Tabela 1. Tanto os ERP proprietários quanto os livres possuem estas características.

- Empresas com processos altamente personalizados: Normalmente este perfil de empresa pouco utiliza as "melhores práticas" existentes nos sistemas ERP proprietários. Estas melhores práticas são uma das justificativas ao alto custo de aquisição inicial de um ERP proprietário. Os ERP livres estudados possuíam somente os processos básicos de melhores práticas, que sofrem pouca alteração, além do custo de aquisição inicial ser baixo. Como exemplo deste tipo de empresas, pode-se citar empresas seguradoras e universidades.

- Necessidade de Ferramenta com Modelo Estruturado pronto para personalização: Ao mesmo tempo, devido ao alto grau de customização e personalização, essas empresas necessitam de uma ferramenta de desenvolvimento provido tanto por sistemas ERP proprietários quanto livres. Nos ERP livres, há a vantagem de normalmente a ferramenta trabalhar com linguagens abertas como JAVA e PHP por um baixo custo de aquisição.

- Empresas em crescimento: Empresas que apresentam restrições a elevados investimentos iniciais na aquisição de sistemas ERP, mas pretendem crescer no futuro próximo.

- Opção ao desenvolvimento interno: Empresas que podem utilizar o ERP como uma ferramenta com modelo estruturado pronto para o desenvolvimento em opção ao completo desenvolvimento interno, inclusive da estrutura e do modelo.

- Empresas que buscam o estado da arte da tecnologia: Normalmente os sistemas ERP livres apresentam o estado da arte da tecnologia, como as mais modernas linguagens de programação e independência totais de escolha de sistemas de software agregados como sistemas operacionais e banco de dados.

Como resultado desta pesquisa, conclui-se também que as principais distinções do software livre se encontram no processo de adoção e seleção, já que o método de implantação se apresentou igual em sistemas ERP proprietário ou livre.

0 fato de somente um sistema ERP livre ter sido selecionado e implantado, justificado pela complexidade da implantação destes sistemas, é uma limitação dos resultados obtidos. Tampouco aspectos como custo e prazo de implantação foram avaliados. Outra limitação é o fato de que o estudo foi realizado em um caso muito específico, uma empresa do terceiro setor (filantropia), sendo necessárias maiores validações e discussões sobre o tema.

Este trabalho aplica-se somente a empresas que avaliem o modelo de uso de ERP na forma de aquisição de licenças ou de propriedade do software, sem levar em consideração modelos como o SaaS (Software as a Service) e ERP na nuvem, que estão relacionados muito mais a serviços que a aquisição ou posse de licenças.

Este trabalho serve como suporte para organizações que avaliam adotar e implantar sistemas ERP livres.

\section{Referências}

Bingi, P., Sharma, M. K., \& Godla, J. K. (1999). Critical issues affecting an ERP implementation. Information Systems Management, 16(5), 7-14.

Bryman, A. (1989). Research methods and organization studies. New York: Routledge.

Buckhout, S., Frey, E., \& Nemec, J. (1999). Making ERP succeed: turning fear into promise. Strategy and Business, 60-73.

Campos, R. R. (2006). Características de Sistemas Integrados de Gestão Empresarial desenvolvidos sob o modelo de software livre: informações para suporte à fase de seleção e viabilidade de instalação em pequenas empresas (Dissertação de mestrado). Escola de Engenharia de São Carlos, Universidade de São Paulo, São Paulo.

Centola, N., \& Zabeu, S. (1999). Pequenas e médias empresas: tomflem a rédea de seus negócios. PC World, 34-54.

Colangelo Filho, L. (2001). Implantação de sistemas ERP: um enfoque de longo prazo, São Paulo: Atlas.

Corrêa, H. L. (1998). Aspectos a considerar na seleção de uma solução ERP para médias empresas: guideline Gestão Empresarial Computerworld. São Paulo. Recuperado em 3 de fevereiro de 2008, de http://www.correa.com.br/ biblioteca/artigos

Corrêa, H. L., Gianesi, l. G. N., \& Caon, M. (1997). Planejamento, programação e controle da produção com MRPII/ERP: conceitos, usos e implantação. São Paulo: Atlas.

Correa, J., Pessôa, M. S., \& Spinola, M. M. (2008a). A model to Map open source ERP at development countries: a Brazil case study. In Proceedings of the International Conference on e-Learning, e-Business, Enterprise Information Systems, and e-Government - WORLDCOM 2008, Las Vegas, USA.

Correa, J., Pessôa, M. S., \& Spinola, M. M. (2008b). Mapping of open source ERP for Brazilian Market. In Proceedings of the 4th International Conference on Production Research - ICPR Americas’2008, São Paulo, BR.

Coughlan, P., \& Coghlan, D. (2002). Action research for Operations Management. International Journal of Operations \& Production Management, 22(2), 220-240. http://dx.doi. org/10.1108/01443570210417515.

Cunha, M. A. L. (1998). Gestão integrada de processos de negócio. In Anais do Simpósio de Administração da Produção, Logística e Operações Industriais. São Paulo, BR.

Davenport, T. H. (1998). Putting the enterprise into the enterprise system. Harvard Business Review, 76(4), 121131. PMid: 10181586.

Deloitte Consulting. (1998). ERP's Second Wave: maximizing the value of ERP_Enabled Processes (Relatório de pesquisa). 
Recuperado em 21 de outubro de 2008, de http://www. dc.com/ whathsnew/second.html.

Durscki, R. (2007). Um ciclo de vida de projetos em melhoria de processos em uma instituição financeira (Dissertação de mestrado). Escola Politécnica de São Paulo, Universidade de São Paulo, São Paulo.

Esteves, J. M., Santos, A. A., \& Carvalho, J. A. (2000). 0 ciclo de vida dos custos dos sistemas ERP, gestão de custos de sistemas de informação. In Anais do $7^{\circ}$ Congresso Brasileiro de Custos. Recife, BR.

Free Software Foundation. (2005). The free Software definition. Recuperado em 14 de agosto de 2006, de http://www.fsf.org

Hehn, H. F. (1999). Peopleware: como trabalhar o fatorhumano na implementação de sistemas integrados de informação (ERP). São Paulo: Editora Gente.

Herzog, T. (2006). A comparation of open source ERP system: wirtschaftsuniversitat wien diplomarbeit. Viena: Viena Universty.

Hexsel, R. A. (2002). Software livre: propostas de ações de governo para incentivar o uso do software livre (Relatório Técnico n. RT-DINF 004/2002). Curitiba: Universidade Federal do Paraná. Recuperado em 14 de outubro de 2008, de http://www.inf.ufpr.br/info/techrep/RT_DINF004_2002.pdf

Informática Exame. (1997, maio). Uma tropa de elite para tocar o negócio. 94-97.

Laurindo, F. J. B., \& Mesquita, M. A. (2000). Material requirements planning: 25 anos de história; uma revisão do passado e prospecção do futuro. Revista Gestão \& Produção, 7(3), 320-337.

Lima, A. D. A. (2000). Implantação de pacote de gestão empresarial em médias empresas. KMPress. Recuperado em 9 de junho de 2000, de http://www.kmpress.com.br

Mendes, J. V., \& Escrivão Filho, E. (2002). Sistemas Integrados de gestão ERP em pequenas empresas: um confronto entre o referencial teórico e a prática empresarial. Revista Gestão \& Produção, 9(3), 277-296.

Miltello, K. (1999, março). Quem precisa de um ERP? Info Exame, 140.

Nakano, D. N., \& Fleury, A. C. C. (1996). Métodos de pesquisa na engenharia de produção. In Anais do $16^{\circ}$ Encontro Nacional de Engenharia de Produção. Piracicaba: UNIMEP, ABEPRO.

Open Source Iniciative. (2006). The open source definition. (2005). Recuperado em 14 de agosto de 2006, de http:// www.gnu.org

Orlicky, J. A. (1973). Net change material requirements planning. IBM Systems Journal, 12(1), 2-29. http://dx.doi. $\operatorname{org} / 10.1147 /$ sj.121.0002.
Portal da Ajuda. (2008). Recuperado em 21 de outubro de 2008, de www.portaldajuda.org.br

Raymond, E. S. (1999). Open source: voices from the open source revolution: a brief history of hackerdom ( 1 ed., pp. 19-31). Cambridge: O'Reilly \& Associates Inc.

Ryman, M. (2004). Open source ERP systems: an investigating study on open source development in ERP systems. Gothenburg: Göteborg Universitet.

Saleh, A. M. (2004). Adoção de tecnologia: um estudo sobre o uso de software livre nas empresas (Dissertação de mestrado). Faculdade de Economia, Administração e Contabilidade, Universidade de São Paulo, São Paulo.

Serapioni, M. (2000). Métodos qualitativos e quantitativos na pesquisa social em saúde: algumas estratégias para a integração. Ciência \& Saúde Coletiva, 5(1), 187-192. http://dx.doi.org/10.1590/S1413-81232000000100016.

Silva, J. F., Costa, 1., \& Pessoa, M. S. (2005). Proposta de um processo de ciclo de vida para adoção de sistemas ERP. São Paulo: USP.

Souza, C. A., \& Zwicker, R. (2001). ERP systems' life cycle: findings and recommendations from a multiple case study in Brazilian companies. In Proceedings of the Annual Conference BALAS 2001 - Business Association of Latin American Studies, San Diego, EUA.

Spinola, M. M., Tonini, A. C., Nomura, L., \& Hikaje, O. K. (2004, novembro). Seleção de sistemas ERP: método e aplicação. In Anais do $24^{\circ}$ Encontro Nacional de Engenharia de Produção (ENEGEP), Florianópolis, BR.

Stamford, P. P. (2000). ERPs: prepare-se para esta mudança. KMPress. Recuperado em 13 de setembro de 2000, de http://www.kmpress.com.br/00set 02.htm

Tonini, A. C. (2003). Metodologia para seleção de sistemas ERP: um estudo de caso. In A. Z. Kelin \& C. A. Souza (Orgs.), Sistemas ERP no Brasil (Enterprise Resource Planning): teoria e casos (Parte 1). São Paulo: Atlas.

Wood Junior, T. (1999). Modas e modismos gerenciais: o caso dos sistemas integrados de gestão (Série de Relatórios de Pesquisa, 16). São Paulo: Núcleo de Pesquisas e Publicações, Escola de Administração de Empresas de São Paulo, Fundação Getulio Vargas.

Yin, R. K. (2002). Case study research: design and methods (3 ed.). Thousand Oaks: Sage Publications.

Zimmerer, T. W., \& Scarborough, N. M. (1994). Essentials of small business management. New York: Macmillan College Publishing Company.

\section{Adoption, selection, and deployment of a freely available ERP Abstract}

In the 1990s, ERP systems achieved widespread use, despite the lack of free ERP software. Interest in free software dates from the first developments in computing in the 1960s and 1970s until the present days. The problem of this research is determining how to adopt, select and deploy an ERP that is freely available. The contributions of this work begin with the proposition of a preliminary model of the ERP life cycle, considering no distinctions between a proprietary and a free ERP. This model was refined using the action research method in a field study focused on the adoption, selection and deployment of a free ERP in a Brazilian company. The main result of this paper is a final model with modifications to the adoption and selection process to use free and proprietary ERP's; one deployment was found not to present process differences.

\section{Keywords}

ERP. Free software. Open source. Action research. 